\title{
SIR RICHARD F. BURTON, EL SINCERO DISFRAZ DEL EMBUSTERO
}

\author{
César RENDUELES
}

\begin{abstract}
Y tantos se exponen a los últimos peligros para vanagloriarse después de una plaza que han tomado, y tan tontamente para mi gusto; y finalmente, los otros se matan para anotar todas estas cosas, no para ser más sensatos, sino solamente para mostrar que las conocen, y estos son los más tontos de la compañía, porque lo son con conocimiento.
\end{abstract}

Pascal. Pensamientos.

Discurre la primavera de 1863. Ya han pasado diez años desde que Sir Richard F. Burton (1821-1890) cobrara pingüe fama tras visitar las ciudades prohibidas del Islam. En esta ocasión se dispone a iniciar una nueva expedición hacia las regiones ignotas del Africa central. Carcomido quizá por esa laudánica melancolía que, aunque inconstante y morosa, fue su inseparable compañera de viaje, escribe una carta a su amigo Monckton Milnes: «Bogando en un tronco ahuecado, a miles de millas río arriba, con tan solo una infinitésima probabilidad de regresar. Me pregunto, ¿̨por qué? y solamente puedo responderme ¡condenado loco!... Lo quiere el diablo». Esta sentencia, probablemente ya la más famosa de Burton merced a la biografía de Brodie que toma de ella su título ${ }^{1}$,

1 Cfr. Fawn M. Brodie: The Devil Drives. A Life of Sir Richard Burton. New York: Norton, 1967. Puede encontrarse un resumen de esta obra en la página web de la Sir Richard Burton Society. La obra de Brodie fue, hasta hace bien poco, la biografía más solvente sobre Burton, honor que ha heredado el ya indispensable trabajo de E. RiCE El Capitán Richard F. Burton (Madrid: Siruela, 1992). No obstante somos muchos los que seguimos apreciando el luminoso entusiasmo, adornado con una divertida pátina vienesa, del libro de Brodie.

ÉNDOXA: Series Filosóficas, n. ${ }^{\circ}$ 13, 2000, pp. 153-164. UNED, Madrid 
recoge el profundo anonadamiento, ese ser conducido por el diablo, que protagonizó la vida de Burton convirtiéndola en la escenificación de un pastiche por el que desfilaron personajes radicalmente antagónicos, intérpretes de una obra que se fue componiendo en el propio obrar. No es una exageración. Si alguien hubiese "escrito" su vida organizándola en clave de ficción hubiera resultado una novela profundamente inverosímil. La gracia de las obras de Burton y, sobre todo, de las biografías que le han retratado, es precisamente ese toque de excentricidad stendhaliano que las hace poco menos que inauditas ${ }^{2}$. Sus extenuantes periplos —de Arabia a Somalia, de Islandia a Estados Unidos, de Brasil a la India...—, su deslumbrante dominio de los clásicos greco-latinos y árabes, su capacidad casi grotesca como lingüista (llegó a dominar veintinueve lenguas e innumerables dialectos), los setenta y dos copiosos volúmenes que escribió o su actividad como agente secreto, conforman una amalgama biográfica absolutamente folletinesca. Por poner un ejemplo especialmente hilarante podemos citar aquella ocasión en que, después de recuperarse del cólera, hacia 1846 , se enamoró perdidamente de una monja, profesora de latín del convento de Santa Mónica, en la colonia portuguesa de Goa. Tras un mañoso cortejo - -escudado tras el disfraz de inglés pío, rico y católico- en el que medió el dolo de una madre superiora cegada por la avaricia, logró persuadir a su amada de que consintiese en fugarse con él. Al fin, una noche drogó a los guardianes que custodiaban el convento y, en compañía de un sirviente musulmán, penetró en la zona donde se encontraban las celdas de las monjas. Desdichadamente, la oscuridad le llevó a cometer un comprometido error, así lo cuenta J.C. Simmons ${ }^{3}$ : «se equivocó y penetró en la celda de la vicepriora, que se encontraba durmiendo. Era una mujer de unos sesenta años. Burton cogió rápidamente aquella forma durmiente y corrió con ella fuera del convento sin descubrir, para horror suyo, el error hasta que no se encontraron en la playa cercana.

"La cagamos", dijo el enfadado Burton, mientras que la vieja dama gritaba aterrorizada. "Qué podemos hacer con esta diablesa ?".

«¿Le cortamos el cuello?», sugirió el sirviente.

2 De hecho, al menos en una ocasión, R. Burton ha aparecido como personaje novelesco. Se trata de la novela de P.J. FARMER - ya clásica para los aficionados a la ciencia-ficción- $A$ vuestros cuerpos dispersos, (Barcelona: Ultramar, 1982) que, al margen de sus méritos literarios, tiene la virtud de proporcionar más datos acerca de Burton que muchas de las biografías al uso.

3 J.C. Simmons: Peregrinos Apasionados. Madrid: Mondadori, 1989, p. 138. 
«No, no podemos hacer eso. Atale los brazos, amordázala con tu pañuelo y déjala. Tenemos que irnos inmediatamente».

La elección de esta aventura no es gratuita, está extraída de uno de las obras que escribió Burton en su juventud ${ }^{4}$, textos plagados de elaboraciones ficticias y, al mismo tiempo, evidentemente autobiográficos. Lo cierto es que Burton, cuando prepara su viaje a las ciudades prohibidas construye su disfraz con la minuciosidad de un novelista. Selecciona con cuidado la nacionalidad que adoptará, el estrato social al que pertenecerá, el oficio e incluso la personalidad de la que hará gala, todo para convertirse en su propio «informador». Así, quien peregrina a la Meca será Mirza Abdullah, médico y derviche afgano; una elegante combinación de caracteres que le permitiría cierto margen de excentricidad que disculpase posibles errores $y$, al mismo tiempo, un galénico acceso a amplios sectores de población. Las hazañas del capitán Burton parecen encontrarse más allá de la distinción entre realidad y ficción, es decir, de la asimilación de ficción y falsedad. Al conseguir fingir convincentemente distintos personajes árabes, pone de manifiesto un ejemplo límite del contacto intercultural, en el que todo conjunto nomológico, incluido el propio bagaje ideológico, se muestra como convencional. De este modo, la propia vida de Richard Burton saca a la luz una ubicuidad de la ficción que, a buen seguro, desesperaría a cualquier avezado deconstructor. En su vida y en sus obras el hipertexto siempre parece adelantarse a cualquiera de los ardides típicos de la microastucia: tras su muerte los médicos descubrieron que su cuerpo estaba literalmente cubierto de cicatrices a consecuencia de su participación en ritos lacerantes sufies ${ }^{5}$, resulta fácil imaginar el gesto de fastidio de cualquier derridiano de pro ante la impertinencia, claramente obscena, que supone tal explicitud de las marcas, tal evidencia de las huellas. De hecho Burton fue duramente criticado en su época por disfrazarse de musulmán, por renunciar a la subjetividad occidental. A este asunto dedica el prólogo a la tercera edición de $M i$ peregrinación a Medina y la Meca, recordando los reproches que otros viajeros (Alí Bey, Buckhardt...) habían sufrido por idéntico motivo. Burton no deja de llamar la atención sobre la índole explícitamente moral de estos ataques, citan-

4 Cf. Goa, and the Blue Montains; or Six Months of Sick Leave, London, 1851.

5 T. WRIGHT achaca estas cicatrices a los combates en los que participó Burton. Sin embargo parece mucho más plausible la hipótesis de Rice, quien afirma que "la causa más probable de las cicatrices perceptibles en el cadáver de Burton ha de ser su éxtasis al implicarse en la sama'y en la danza de las espadas propias de los khanqahs sufíes"(Rice, op. cit., p. 537). 
do algunos de los más llamativos: «no es este el lugar para discutir la moralidad de un acto que implica la deliberada y voluntaria negación de lo que el hombre considera ser la verdad en materia tan sacra como la Religión. Semejante violación de la conciencia no puede justificarse por la meta que el renegado tiene ante sí» ${ }^{6}$. De alguna manera Burton fue plenamente consciente del carácter siempre fronterizo de su vida, de estar viviendo en un peculiar límite en el que toda costumbre (religiosa, sexual, militar, literaria...) se presenta como una invención que es posible imitar ${ }^{7}$. Así, no pudo dejar de señalar en el libro que cierra su producción centrada en la India lo fácil que resultaba en el Este crear «extrema confusión entre Realidad y Ficción" ${ }^{8}$. Resulta desconcertante la naturalidad con que logra escapar a la falacia de la sinceridad unívoca, esa extendida creencia en que a todo disfraz subyace un fondo de bonradez con uno mismo. La plenitud personal queda anulada en el momento en que se comprueba que no es más que una perspectiva ideológica más, una de las múltiples posiciones que se puede adoptar en un sistema de reglas cuya calidad privilegiada aniquila el disfraz, al mostrar la contingencia de todo juego. Sigilosamente, sin darle mayor importancia, Burton disuelve la escisión entre una vida interior, lugar de la verdad y la certeza, y una exterioridad susceptible de mentir, de engañar a través de miles de añagazas, para establecer así un contexto de validez cercano a lo poético: «se debe preferir lo imposible verosímil a lo posible inverosímil", aunque también «es verosímil que sucedan cosas al margen de lo verosímil» ?. Términos que al abandonar el universo de la poiesis para trasladarse, a través del disfraz, al mundo de las acciones adquieren un curioso espesor praxeológico. No en vano ha sido amplio motivo de discusión la cuestión de si Burton era o no verdaderamente musulmán. Sin lugar a dudas se trata de un debate enteramente espurio. Muy tempranamente Burton adoptó la táctica que utilizaban los ismaelíes para defenderse de los musulmanes ortodoxos: el encubrimiento de las propias creencias o taqiya. Se forma así un extraño círculo de herejías.

6 Apud. R.F. BurTon, Personal Narrative of a Pilgrame to Al-Madinah \& Meccah (trad. esp. Mi peregrinación a Medina y la Meca (3 vol.); Barcelona: Laertes, 1983-85, vol I, p. 18).

7 El proceder mimético de Burton no se limita a sus disfraces. Así, por ejemplo, su traducción del Kama Sutra consiguió convertir la obra en un clásico del erotismo a base de enmendar con sus conocimientos el original que, en comparación, resulta más bien tedioso y algo pedestre. Tampoco hay que olvidar el texto que recoge una síntesis del pensamiento de Burton, The Kasidah, escrito siguiendo pautas poéticas sufíes y bajo el seudónimo de Haji Abdu El-Yezdi.

8 Falconry in the Valley of the Indus. London, 1852, p. 87.

9 Aristóteles, Poética, 60a26-27 y 61b15. 
Porque, en efecto, lo que apasiona de Burton es que sus embozos carecían de toda vocación trocaica, no fue sólo un espía al servicio de su majestad que de cuando en cuando se disfraza de derviche para mejor intrigar contra el moro infiel. Este sí es el caso de T.H. Lawrence, su vocación arábica jamás dejo de mostrarle como lo que era: un agente secreto, ligeramente alienado pero de una eficiencia inaudita. Pocas dudas caven ya de que la principal actividad profesional de Burton fue la de espía - un peón más en la compleja partida colonial decimonónica, a menudo zarandeado por las decisiones de la "alta política" imperial tan alejadas del campo de batalla - pero, curiosamente, es ese el único aspecto de su vida del que apenas tenemos noticias ${ }^{10}$. Da la impresión de que, a fin de cuentas, su uniforme de soldado no deja de ser el disfraz bajo el que se esconde un apasionado filólogo que aprovechó su destino militar en la India para estudiar y comenzar a trabajar en la traducción de las monumentales obras maestras de la literatura erótica que, no sin cierto malicioso aire de contubernio, introdujo en la sociedad victoriana. Pero, al mismo tiempo, tras su máscara de erudito se guarece un joven que se empecinó en ser expulsado de Oxford, que despreciaba profundamente el mundo académico y gustaba de romper las pueriles jerarquías universitarias retando a duelo a aquellos estudiantes que se reían de sus excentricidades. Burton es un espía inglés en Oriente... o el quintacolumnista de la barbarie en Inglaterra. Si vamos despojando cada brinza de esta especie de cebolla biográfica probablemente sólo nos quede al final el retrato de un bromista. El mismo que dijo haber descubierto a los descendientes de las diez tribus perdidas de Israel - despertando la admiración de los especialistas en la materia- o escribió un informe militar acerca de los prostíbulos indúes ligeramente más documentado de lo que la moral castrense permitía ${ }^{11}$.

10 Sin lugar a dudas el mayor misterio respecto a la vida de Burton, al margen de los distintos intereses más o menos cotillas de sus biógrafos, sigue siendo el de su viaje por los Estados Unidos, que Burton aprovechó para visitar Salt Lake City, la ciudad de los mormones [Viaje a la ciudad de los santos (El País de los Mormones), Barcelona: LAERTES, 1986]. En concreto, el misterio se centra en torno a la época que pasó en Nueva Orleans, poco antes de que estallara la crisis que escindiría la Unión, en un momento en que Inglaterra tenía considerables intereses en apoyar la causa sudista.

11 Se trata, por supuesto, del famosísimo Epilogo a las Mil y Una Noches (Barcelona: LAERTES, 1989), editado también bajo el título The Sotadic Zone, en el que se da cuenta de las costumbres sexuales en los países islámicos. A pesar de lo mucho que se ha escrito sobre este ensayo a uno le acaba quedando la sensación de que su tono arcaizante, su explicaciones de las costumbres en términos climatológicos o la exuberante erudición desplegada, corresponden más a una cuidadosa broma que a alguna clase de militancia homosexual. 
Y pese a todo, hasta aquí nada hay de sorprendente, tan sólo un retrato más de una de esas vidas violentas y agitadas, uno de esos periplos biográficos que, muy en el fondo, a todo heredero de las luces ilustradas le hubiera gustado recorrer. La peculiaridad que lo distingue y de la que tan sólo Alberto Cardín parece haberse ocupado con un mínimo de seriedad, es que su trabajo como etnógrafo goza de un rigor insoslayable. Sus disfraces dejan de parecer entonces una pura burla. Sus máscaras de derviche o de jeque que le permitieron viajar por tierras prohibidas a los occidentales, se muestran de golpe como una instancia gnoseológica de un valor incalculable, toda vez que, como escribe Cardín, los detallados informes de Burton acerca del mundo árabe sólo puede compararse a la Enciclopaedia of Islam ${ }^{12}$. En Burton no hay observación participante, ni antropologos y autores, ni etnografía reflexiva, ni militancia antiimperialista ni mucho menos cárceles lingüísticas. Nada que impida dar cuenta de que la auténtica dificultad con la que tropieza la etnografía es la de no ser capaz de pasar por nativo. El plano «objetivo» de la obra de Burton, la excepcional y convincente representación del Islam que facilita, está brutalmente legitimada por el hecho de que, al menos para los musulmanes - si «engañados» o no es precisamente lo que hay que discutir- era musulmán. Cuando Burton ofrece un dato empírico sobre el Islam necesariamente sabe lo que se dice, la prueba irrefutable es que sobrevivió para escribirlo. Buena cuenta de ello da aquella historia que, siempre fanfarrón, tanto le gustaba contar. Cierta noche en que se encontraba en el desierto se alejó de la caravana para orinar. Puede que la oscuridad le hiciera confiarse y bajar la guardia, el caso es que comenzó a orinar de pie, a la manera occidental, y no en la postura que adoptaban los árabes. Un muchacho que casualmente pasaba por allí le vio, comprendiendo inmediatamente que era un impostor. Burton, al saberse descubierto, no lo dudó un instante, se abalanzó sobre él y lo acuchilló. Las infinitas contingencias no permiten un respiro, en ningún momento se puede dejar de ser musulmán:

Finalmente llegamos al otro lado del Darb, donde a punto estuve de descubrirme al confundir el destartalado lugar de entierro de los cismáticos Najawilah con Al-Bakia, el glorioso cementerio de los Santos. Hamid corrigió mi error con aspereza, a lo que yo repliqué con no menor acritud, diciendo que en mi país - Afganistán-quemábamos los cadáveres de todos los herejes que caían en nuestras manos. Tal costumbre, verdaderamente islámica, fue escuchada con general aprobación ${ }^{13}$.

12 Prologo a la tercera edición española de Mi peregrinación..., op. cit., vol. I, p. 10.

13 R.F. BuRTON, Mi peregrinación..., op. cit., vol II, p. 163. 
La "metodología» etnográfica de Burton exige un minucioso disfraz pragmático en el que se comienza a conocer al otro desde el momento mismo en que se empieza a ser el otro. Por eso, como el propio Cardín señala, su escritura es reconstructiva, sus textos se alejan enormemente de la típica narración decimonónica de un viaje. Se trata de una construcción enteramente operatoria que, sin llegar a elaborar estructuras teóricas, marca parámetros praxeológicos que legitiman la etnografía como, si no verdadera, al menos sí fiable. Resulta curioso verificar que los textos de Burton, quizás quien más razones tenía para convertir sus libros en novelas freudianas, adolecen de una tediosa minuciosidad. $\mathrm{Ni}$ siquiera hace falta comparar su severo estilo narrativo con el atormentado romanticismo de Lawrence, basta comprobar como Stevenson consigue convertir un paseo en burro por la campiña francesa en una suerte de periplo míti$\mathrm{co}^{14}$, o la forma en que Goethe transforma un señorial viaje a Italia en poco menos que una experiencia mística. Aun más, Burton puso mucho cuidado en señalar cuales eran los límites pragmáticos de su "narración personal», en explicar por qué a la hora de narrar sus viajes - y a diferencia de otros viajeros occidentales, como acertadamente señala Goytisolo ${ }^{15}$ — se desprende de su disfraz:

quizás algunos muestren curiosidad por saber las medidas que hube de tomar para poder aparecer de pronto como un oriental en medio del escenario de la vida oriental, y puesto que tal relato puede resultar útil para futuros aventureros, no intentaré disculparme por la apariencia egotista de mi narración ${ }^{16}$.

Precisamente la única referencia que la «nueva antropología» hace a la obra de Burton ${ }^{17}$ es para situarlo en ese contexto del viaje "personal" — quizás "turístico" sería un calificativo más apropiado- que tanto parece gustar a Crapanzano, Rabinow y compañía. La antropología postmoderna y sus complicados epiciclos no han conseguido sino la definitiva eliminación de una instancia, tan básica en las compresiones políticas clásicas, como es el estatuto de extranjero. Los procelosos remordimientos "post-humanistas» que persiguen a

14 Cf. R.L. SteVEnSON, Viajes con una burra, Barcelona: Edhasa, 1971.

15 Cf. J. Gortisolo. Crónicas Sarracinas, Barcelona: Ruedo Ibérico, 1982.

16 R.F. BurTon, Personal Narrative of a Pilgrame to Al-Madinah \& Meccah (trad. esp. Mi peregrinación a Medina y la Meca (3 vol.) ; Barcelona : Laertes, 1983-85).

17 Tan sólo M.L. Pratt se ha ocupado, siquiera perifericamente, de Richard Burton: "Fieldwork in Common Places" en Clifford and Marcus (ed.), Writing Culture, Berkeley: University of California Press, 1986. 
la última camada de antropólogos norteamericanos, han borrado el horizonte etnográfico de comprensión de la barbarie ${ }^{18}$. Sin embargo, se trata de una categoría perfectamente clara para Burton, su admiración sin límites por la civilización musulmana, que consideraba muy superior a la cristiandad, en ningún momento fue óbice para que expresara crueles prejuicios, con todos los visos de haber sido cuidadosamente elaborados, en relación a otros pueblos. En realidad resulta muy interesante comprobar como la categorización del extranjero cambia para Burton en los distintos "papeles" que representa. En una misma obra alaba primero las costumbres árabes para, pocas líneas más abajo, mostrarse quejoso de la barbarie que le rodea. Así, en otra carta a Milnes, escrita también en la época en que era cónsul en la isla africana de Fernando Poo, escribe:

Me proponía, con una curiosidad prodigiosa, ver a cinco mil vírgenes africanas adultas, por no haber conocido nunca un sólo espécimen. Descubrí que la mayor parte habían sido descubiertas en flagrante adulterio, y entregadas al rey para su uso personal, en vez de haber sido ejecutadas. Eran casi todas ya viejas, y todas repugnantes. A las oficiales las habían escogido decididamente por el tamaño de sus traseros.

Quizás no sea mera retórica afirmar que Burton mimaba sus propios prejuicios, los conocía y cultivaba exhaustivamente porque conocía su valor. Sus disfraces no consistían sólo en ropajes orientales, una circuncisión y la piel teñida con alguna substancia bituminosa. Debía conocer todos y cada uno de los gestos que componen una cultura, desde con que mano se agarra la comida, hasta los comentarios varoniles que ante un grupo de amigos se debe proferir. Un buen ejemplo de esto último es un bello párrafo donde describe, con una minuciosidad endiablada, la forma en que se debe beber un vaso de agua si se desea pasar por musulmán. Se traza así la abrupta frontera que separa, y al tiempo une, la descripción y la acción, de forma tal que es ya imposible considerar la cultura como una totalidad expresiva en la que cada sujeto refleja la identidad del conjunto. Aquí la etnografía consiste en adoptar un lugar peculiar de la acción en el entramado social que se describe; requiere, por tanto, una dolorosa labor pragmática de mediación. El disfraz establece momentáneamente una determinación diferencial que nunca acaba de clausurarse, en la medida en que se distancia de cualquier identidad "interior" aparentemente fijada para siempre. Es decir,

18 Llegados a este punto resulta obligada la referencia a una de las grandes asignaturas pendientes de la antropología de nuestro país, se trata por supuesto de la obra de Gustavo BuENO Etnología y Utopia, Gijón, Jucar, 1987 [1. ed. 1971]. 
muestra la contingencia de cada papel reificado, tanto el propio como el ajeno. Uno nunca se disfraza simplemente de "árabe», es importante que la máscara esté escrupulosamente detallada, determinada hasta en sus más nimios detalles. $\mathrm{El}$ disfraz se va definiendo con tal minuciosidad que se convierte en acto, de forma que su cierre conceptual pasa a ser contingente. cualquier clausura demasiado forzada es literalmente peligrosa, pues es susceptible de ser aniquilada por algún movimiento pragmático. Nada tiene que ver esto con ninguna clase de escepticismo, más bien traza la índole crítica de toda reflexión racional sobre los grupos humanos, la referencia de las ciencias humanas a eso que antes se llamaba politi$c a$. En realidad, no estamos exponiendo nada mas que lo que "de hecho" ocurre en todo buen trabajo de campo ${ }^{19}$. Lo excepcional es que Burton consigue superar las medias tintas en las que, por razones obvias, suele quedarse cualquier etnógrafo con un adarme de sentido común, y realizar así un trabajo de campo modélico, un trabajo de campo llevado a su límite último. Tan ejemplar fue su contacto con la alteridad que parece disolverse su propia identidad personal, nunca se sabe cuál es la posición de la sinceridad en su vida y en su obra. Aparecen curiosos bucles, nuevas máscaras superpuestas. Así, disfrazarse de peregrino musulmán también significa, literalmente, disfrazarse como se disfraza un peregrino musulmán:

Posteriormente pude ir viendo de qué modo todos mis compañeros de viaje iban metamorfoseándose de manera igualmente notable. Como hombres sensatos que eran, aparecían en harapos allí donde eran, o deseaban ser, desconocidos, y vestían con finos trajes donde y cuando el mundo debía juzgar su prosperidad en vista de su atuendo ${ }^{20}$.

A partir del siglo XIX se ha ido desarrollando una verdadera autoconsciencia antropológica, las visicitudes de la "cultura" han superado con creces el ámbito académico. Sin embargo, esta es una textura ideológica a la que Burton es irreverentemente ajeno. "Cultura" para Burton sigue siendo poco menos que sinónimo de erudición, de civilización, y no esa triste reminiscencia de la vieja noción de raza, que hoy se camufla bajo el nombre de «etnia». Por eso el colonialismo de Burton es plural y extrañamente crítico, se sitúa al borde mismo de lo científico. A veces es un soldado inglés dispuesto a hacer todo lo posible por ampliar los límites del imperio, en otras ocasiones es un refinado

19 ¿Será necesario recordar el trabajo de W.F. WHYTE, Street Corner Society?

20 R.F. BURTON, Mi peregrinación..., op. cit., vol. II, p. 11. 
musulmán que desprecia profundamente la vulgaridad occidental. Burton en ningún caso acepta la nivelación acrítica de todos los grupos humanos entre sí, más bien parece establecer el lugar del disfraz como límite mismo de esa nivelación. En la posibilidad de adoptar el prejuicio que envuelve al disfraz se expresa la frontera pragmática en la que toda costumbre, propia o ajena, se convierte en ficticia sin llegar a ser falsa. Un límite cuya piedra angular es precisamente la posibilidad de discernir dos polos conjugados, una pluralidad - constatada como tal por el disfraz- que internamente - desde el prejuicio que la acompaña- es isoglósica. Por eso Burton ha ocupado siempre una posición ambigua para sus lectores de este siglo, por una parte se le ha considerado un ferviente antiimperialista y por otra una especie de taimado colono ${ }^{21}$. Una tensión que ningún biógrafo ha dejado de señalar. Lo cierto es que incluso en sus libros, que escribe aceptando sin ambages su papel de británico (uno se siente tentado de decir "bajo su disfraz de británico"), hay duras críticas al colonialismo pero, en no menor número, indicaciones estratégicas para mejorar la posición del imperio ¿Qué clase de espía es un hombre que acepta entusiasmado sus misiones, ansiando alejarse de las «afeminadas» costumbres del país al que sirve? ¿Qué clase de antiimperialista hace planes para conquistar el corazón mismo del Islam?:

sería aconsejable estar representados en el Hiyaz por un cónsul, y en la Meca por un agente nativo, hasta que sea llegado el día en que la marea de los acontecimientos nos obligue a ocupar la ciudad madre del Islam. Mi disculpa por volver sobre este punto debe ponerse por cuenta de mi naturaleza de inglés, que no puede sufrir ver su nación "por detrás de nadie», ni siquiera en Yeddah ${ }^{22}$.

Hablar de influencia sería de una ingenuidad atroz pero, aun a sabiendas de los peligros que encierran los remedos plutarcianos, es difícil vencer la tentación de encontrar misteriosas líneas comunes entre Richard Burton y Pascal. Burton aparece casi como la inversión especular de la "conversión" pascaliana, el opuesto punto por punto de una misma imagen. Vidas extravagantes, desconcertantes para sus contemporáneos, que sacan a la luz la misma "falsedad". Pascal renuncia a lo mundano, al divertissement, como ámbito del juego, de la

21 Dos ejemplos meridianamente claros son, respectivamente, los trabajos de GoYTisolo (op. cit.) y E.W. SAID , Orientalismo, Madrid: Libertarias, 1990.

22 R. BURTON, Mi peregrinación..., op. cit., vol. III, p. 104, n. 13. 
instauración de sistemas de reglas constitutivas que proporcionan elencos de posibilidad de sustracción a la temporalidad cotidiana. Su atormentada introspección culmina en el descubrimiento de que aquello que parecía el yo, la substancialidad por excelencia, es en realidad una pura y simple nada. El juego evita que el yo se enfrente a la ausencia de plenitud que define su esencia, por eso la conversión se cifra en términos de una auténtica aniquilación a través del rigorismo ascético. Nada hay al margen de los sistemas de reglas convencionales, incluso la geometría, como escribe Pascal en una carta a Fermat, no es más que un entretenimiento trivial. El establecimiento de una continuidad de espacios ficticios de representaciones codificadas, evita la melancolía que sucede a la consecución de los objetivos, siempre triviales, que componen la vida social. La complejidad reticular de los símbolos encubre ese anonadado descubrimiento de lo menesteroso, por contingente y convencional, de los espacios mundanos. La vida entera de Burton es, en cambio, una auténtica hipertrofia del "divertimento». Perseguido por un tedio acuciante no duda ni un instante en probar todo «juego", cuanto más peligroso mejor, que se le pone por delante (drogas, caza, guerra, sexo, viajes...). A fin de cuentas, qué mejor juego que la lengua: en los idiomas se comprueba la naturaleza constitutiva de las normas, la diferencia entre lengua y habla proporciona el horizonte de comprensión de un juego al que nunca se puede dejar de apostar, una partida a la que estamos abocados indefectiblemente. $Y$ tanto que Burton aceptó la partida, precisamente una de las causas de su fama fue su extravagante capacidad para aprender un idioma en escasísimo tiempo. En ese aventurarse en cualquier juego, viviendo la propia vida como si de una representación teatral se tratase, se muestra un nuevo anonadamiento pascaliano, el yo desencalla de las arenas de la identidad etnocéntrica, para naufragar en las aguas de la multiplicidad. Del mismo modo que la conversión descubría que nada había tras la máscara, el disfraz llevado a su extremo hace olvidar lo que había tras la máscara. Ya sólo queda perplejidad y tristeza ${ }^{23}$. Si la conversión nos enfrenta a Dios como una nada esencial frente a su plenitud, el disfraz y la aventura, la plenitud de la acción, nos acercan a una nueva inesencialidad, a una hipertrofia del juego y la ficción que, como el propio Burton señaló, sólo puede estar guiada por...el

23 Como nos recuerda Giorgio Agamben (Estancias, Valencia: Pre-Textos, 1995, cap. I y II) la tristitia formaba parte de los pecados capitales que, en las más antiguas tradiciones patrísticas, eran ocho y no siete. Posteriormente la tristitia fue absorbida por la acedia para, más adelante, converger con la melancolía. 
Diablo. Diabólica y herética fue su obsesión por visitar las ciudades santas, gozando de mayor satisfacción cuanto más peligrosa fuera la empresa ${ }^{24}$. Diabólica y herética fue su actividad como editor de obras eróticas en su propio país. Siempre fementido, Burton vivió melancólicamente esa fuerza que proporciona la ubicuidad de una acción que se sabe al mismo tiempo contingente y perentoria. Cuando Frank Harris ${ }^{25}$ se lo encontró, ya anciano, no sólo le sorprendió su aspecto de ermitaño salvaje sino, sobre todo, su aire de tristeza fúnebre. Para Harris era evidente que "en lo más profundo de su ser latía la lúgubre desesperación de una incredulidad absoluta».

24 Quizás el viaje más arriesgado de Burton fue el que le llevó a la ciudad de Harar: R. BURTON, Primeros pasos en el este de Africa. Expedición a la ciudad prohibida de Harar. Barcelona: Lerna, 1987.

25 Frank HARRIS, Contemporary Portraits, Nue'a York, 1963. 